\title{
Survey of Media Forms and Information Flow Models in Microsystems Companies
}

\author{
Christopher Durugbo, Ashutosh Tiwari, and Jeffery R. Alcock \\ School of Applied Science, Cranfield University, Cranfield, United Kingdom \\ \{c.durugbo,a.tiwari,j.r.alcock\}@cranfield.ac.uk
}

\begin{abstract}
The paper presents the findings of a survey of 40 microsystems companies that was carried out to determine the use and the purpose of use of media forms and information flow models within these companies. These companies as 'product-service systems' delivered integrated products and services to realise customer solutions. Data collection was carried out by means of an online survey over 3 months. The survey revealed that $42.5 \%$ of respondents made use of data flow diagrams and $10 \%$ made use of design structure matrices. The survey also suggests that a majority of companies (75\%) made use of textual and diagrammatic media forms for communication, analysis, documentation and representation during design and development processes. The paper also discusses the implications of the survey findings to product-service systems.
\end{abstract}

Keywords: Information flow, Modelling, Services, Product-service systems, Microsystems.

\section{Introduction}

This study focuses on a sample of microsystems companies to consider accessibility issues for product-service systems (PSS) but in particular information flow by means of media forms and models. Determining the use and purpose of use of media forms and information flow models could be useful in improving the delivery of products and services realised from microsystems production. This is because a PSS applies 'social constructs' that require information flow to manage the delivery of value propositions based on closely linking and offering products and services [1]. Furthermore, information flow knowledge is key to the implementation of standards for quality, efficiency, and financial performance in the delivery of customer solutions as defined by ISO 9000 and ISO 14000 [2].

The main aim of this paper is to capture industry practice in the use of media forms and information flow models for the delivery of product-service systems.

The remainder of this paper has been structured as follows. Section 2 describes the novelty of the research while Section 3 identifies common information flow models in literature. Section 4 outlines the methodology for the research. Section 5 presents the findings of the study while Section 6 discusses the implication of the study for PSS. 


\section{Contribution to Technological Innovation}

As microsystems production moves from a 'surprise to enterprise' [3] phase, it is important to examine current applied tools. This paper investigates information flow modelling in microsystem companies that apply PSS and seeks to contribute to technological innovation by:

1) establishing if there are correlations in the information flow models for PSS proposed in literature and those actually employed in industry

2) comparing and contrasting the various media forms employed for information flow during microsystem production

To the best of our knowledge, no previous study of this kind has been undertaken for the microsystems domain.

\section{Information Flows for Product-Service Systems}

A Product-Service System (PSS) has been defined as 'an integrated product and service offering that delivers value in use' [4]. Value in use for a PSS is realised in a function-oriented business model highlighting the importance of information flow for the delivery of products and services by a manufacturer to a costumer [5].

Information flow is based on information gathering [1] by means of textual, audio, video and graphical media forms [6]. These media forms are used for communication within an organisation [7], for description of processes [8], for analysis of systems [9] and for the documentation of ideas, activities and processes [10].

A useful way of representing information flow in a system or an organisation is by means of information flow models that depict system functions and architectures [5]. Diagrammatic tools in particular have been suggested for information flow modelling because these tools require less storage and are processed more efficiently in humans [11]. Function-oriented diagrammatical information flow models such as data flow diagrams (DFD), Integrated DEFinition (IDEFØ), Graphes à Résultats et Activités Interreliés (GRAI) grids, Petri nets, Input-Process-Output (IPO) charts and Design Structure Matrices (DSM), provide useful means for representing information flow in a PSS [5]. DFD can be used in organisations to propose information flow paths (logical view) and to represent actual flows (physical view). DFD depict processes, external entities, data stores and flows in sequential representations. Information flows in manufacturing can be highlighted by the IDEF $\varnothing$ approach by means of boxes that depict processes, and arrows that indicate inputs, controls, outputs, and mechanisms associated with a function. GRAI grids provide information flow descriptions to support decision making processes in an organisation or a system. Petri-Nets deliver representations of information flow in the development and simulation of eventdriven and automated manufacturing systems. IPO charts offer information flow descriptions in programs but can also be extended to describe systems with varying complexity. DSM offer compact, visual, matrix representations for systems analysis to offer a roadmap of system level knowledge. 


\section{Research Methodology}

This study was undertaken in four stages: literature review, state-of-the-art in industry, online questionnaire and data representation.

The research began with a literature review of function-oriented diagrammatic models for product service systems [5]. The second stage considered the state-of-theart in industry for product-service systems within the microsystems industry based on a sample of 100 microsystems companies [12]. The sample was made up of a random selection of members of organisations (MEMS Industry Group, IVAM and SEMI) for companies aiming to carry out business transactions within the microsystems industry. These companies are headquartered at locations in Europe (56\%), North America $(38 \%)$ and Asia (6\%). For the third stage, a questionnaire was developed and distributed with pre-defined responses (and the option of a user-defined response) from participants over a period of 3 months. The questionnaire inquired about the use and the purpose of use of media forms and information flow models in microsystems production through questions such as 'What are the major considerations in the choice of media forms?' and 'What modelling techniques have you used as part of your duties?' Responses to the questionnaires were solicited in three ways: firstly, via electronic mail containing the questionnaire, secondly, by means of an online survey site for which participants were allocated a unique ID to maintain traceability and confidentiality, and thirdly, by means of follow up telephone calls. 40 companies completed the questionnaire. A breakdown of the types of companies that completed the questionnaire is presented in Table 1.

Table 1. Breakdown of survey respondents

\begin{tabular}{lc}
\hline Type of Company & Number of Survey Respondents \\
\hline Microsystems foundry & 8 \\
Microsystems manufacturer & 22 \\
Computer-Aided Design (CAD) developer & 3 \\
Intellectual Property (IP) company & 2 \\
Consulting firm & 2 \\
Microsystems distributor & 3 \\
\hline
\end{tabular}

For the fourth stage, data representation was undertaken by means of column charts that show the results of the study. Responses to each question in the survey were aggregated and presented in a column chart that compared the aggregated responses.

\section{Research Findings}

In terms of media forms, the survey revealed that 40 of the respondents made use text formats (electronic mail, facsimile and text files) while 34 of the respondents applied graphical representations (diagrams and charts) for the flow of information. Audio and video formats, on the other hand, were used by 16 and 21 of the respondents respectively as shown in Fig. 1. 


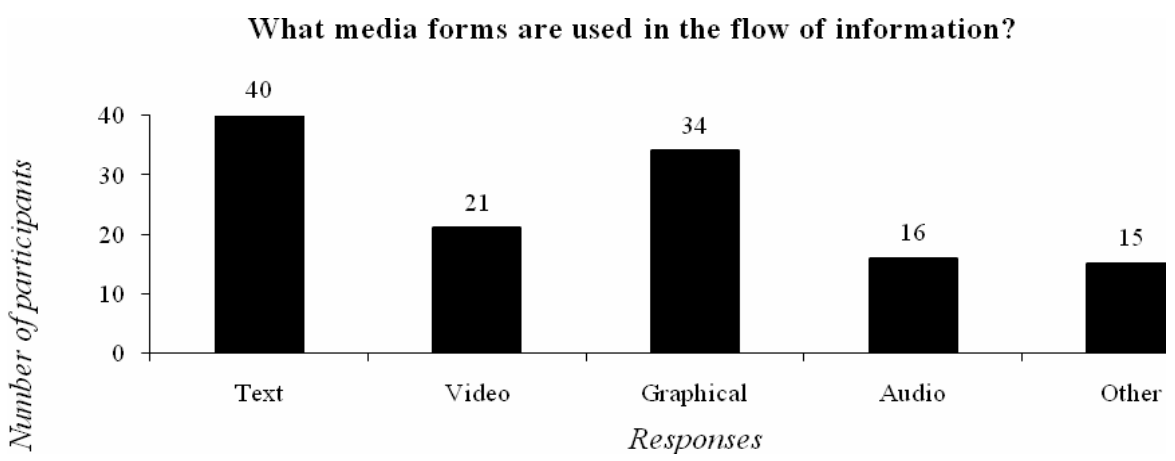

Fig. 1. Media forms for microsystems production

$15 \%$ of the respondents noted the use of software based simulation and 3D simulation /animation by means of Computer-aided design (CAD) tools as key to information flow during design and development. $12.5 \%$ of the respondents noted that popular information technology formats especially slide presentations, video conferencing and internet/intranet websites were crucial to the flow of information for the design and development of microsystems. 1 of the respondents noted the use of physical prototypes as a means of information flow. $10 \%$ of the respondents also noted that information flow by face-to-face and word of mouth was applied to complement their companies' media forms because they were small and new companies to the microsystems industry.

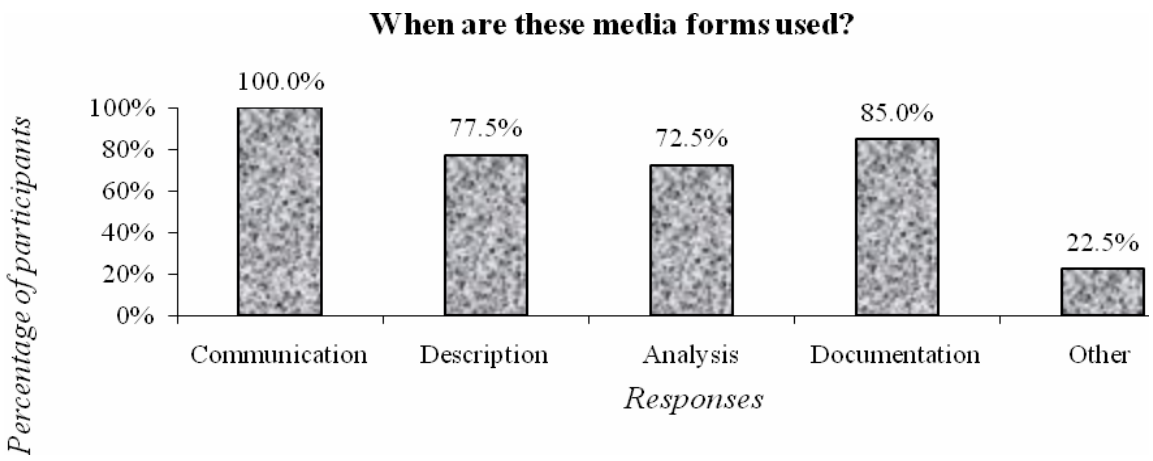

Fig. 2. Purpose of use for media forms during microsystems production

In terms of the purpose for using media forms (the question posed was 'When are these media forms used?'), $100 \%$ of the respondents chose various media forms based on use for communication, $77.5 \%$ for description of functions and processes, $72.5 \%$ for analysis of systems and $85.0 \%$ for documentation (as shown in Fig. 2). Other uses of media forms captured by $22.5 \%$ of the survey respondents included: for presenting results and for conversations to clarify concepts or rectify issue. 
What are the major considerations in the choice of these media forms?

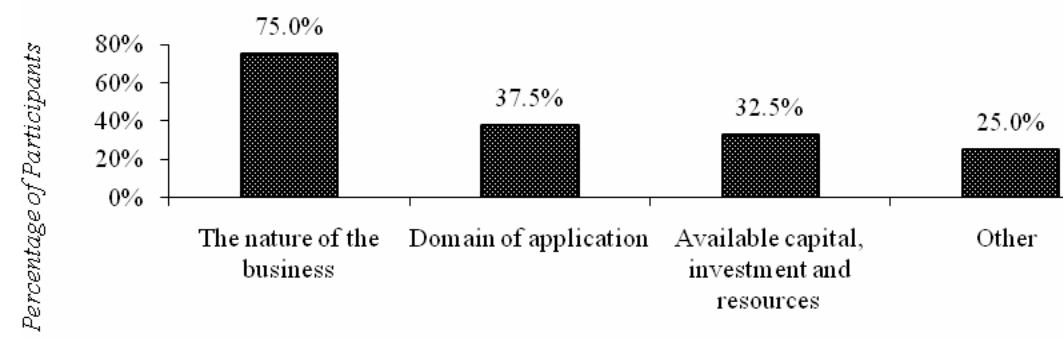

Participant Responses

Fig. 3. Major considerations for selecting media forms during microsystems production

In relation to major considerations for selecting media forms, the study revealed that $75.0 \%$ of the respondents chose various media forms because of the nature of their business, $37.5 \%$ because of the domain of application, and $32.5 \%$ because of available capital. Other considerations for the choice of media forms include: standard industry practice, ease of communication, effort required to generate the material vs. the communication value, ease of use and convenience. These other considerations were noted by $25.0 \%$ of the survey respondents as shown in Fig. 3.

For information flow models, the survey showed that 17 of the respondents applied DFD as part of their duties, 4 respondents made use of DSM while 17 of the respondents did not make use of any of the information flow models identified in Section 2. All respondents that made use of DSM also made use of DFD. None of the respondents made use of IDEFØ, Petri Nets, GRAI or IPO charts as shown in Fig. 4.

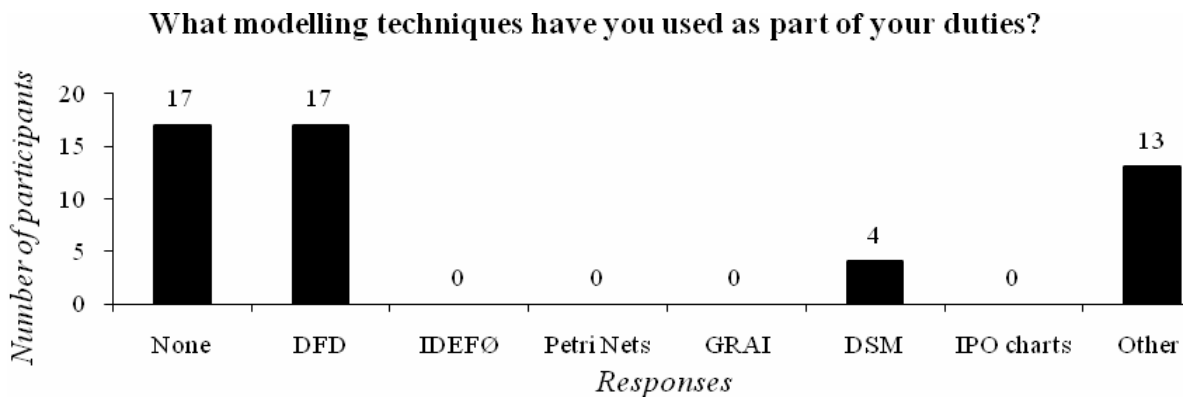

Fig. 4. Diagrammatic models for microsystems production

$32.5 \%$ (13 from 40) of the respondents noted the use of other forms of diagrammatic tools such as engineering block diagrams, Gantt charts, timing diagrams, software development tools, enterprise resource planning (ERP) tools and project management tools based on methodologies such as PRINCE2 (PRojects IN 
Controlled Environments). 5\% of the respondents also noted the use of intuitive and individual approaches for generating diagrams to carry out tasks.

The study revealed that when asked what diagrammatic tools were used to model, $50 \%$ (20 from 40) of the respondents answered for products while $17.5 \%$ ( 7 from 40) answered for services. $12.5 \%$ ( 5 from 40 ) of the respondents made use of diagrammatic tools to model both products and service.

In relation to the purpose of using modelling tools, the study showed that $50 \%$ of respondents applied modelling tools for the design and development of products as shown in Fig. 5. 15\% of respondents made use of modelling tools to design services while $17.5 \%$ of respondents made use of modelling tools to develop services. Other purposes of use identified by $12.5 \%$ of respondents include: for customer support, for quality planning, for managing the life of software development, to explain products and services to customers, for research and quality control, and for the delivery of services and products.

When are these modelling tools used?

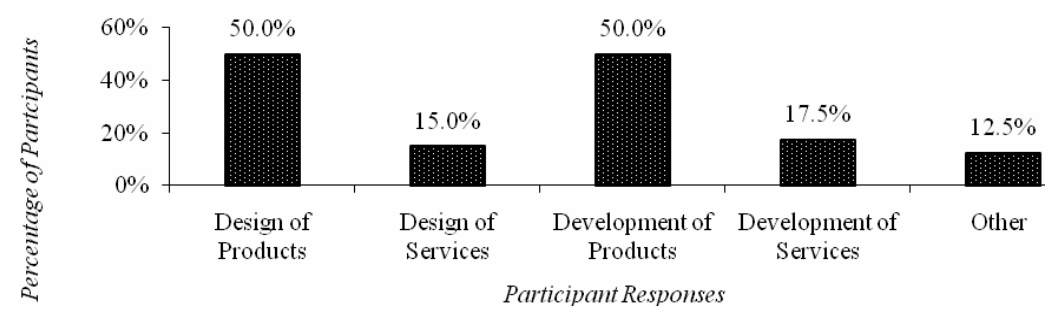

Fig. 5. Purpose of use for diagrammatic models during microsystems production

\section{Implications for Product-Service Systems}

The implications of this study are threefold: emphasis on business-driven information flows, simplicity of information flows and trade-offs between creativity/conformity in approaches to managing information flow.

With regards to business-driven information flows, the study suggests that most companies ( $75.0 \%$ of survey respondents) considered the nature of their business the major consideration for choice of media forms. The microsystem businesses studied included foundries, manufacturers, CAD developers, IP companies, consulting firms and distributors. Consequently, the decision by a microsystem company to make use of media forms is dependent on the type of products and services offered. For instance, a CAD developer could prefer information flow by means of software based simulation whereas microsystems distributors could lay greater emphasis on information flow by means of internet websites. Furthermore, the use of modelling tools as highlighted in the study, supports product/service design, product/service development and in one case product/service delivery.

In terms of simplicity of information flow, the study highlights two key themes: ease of use and informal information flows. As suggested by this study, text and 
graphical forms (the simpler media forms) scored higher among respondents. Furthermore, in Perry et al. [6] the use of face-to-face or word of mouth, though not media forms, are identified as common and informal forms of communications. Consequently, although this was not asked as part of the questionnaire, it is assumed that this is the case for all participating companies for two main reasons. Firstly, information flow by face-to-face contact and word of mouth are natural forms of information exchange and secondly, these forms of communication offer useful avenues for informal flow of information.

The study also highlights the importance of considering trade-offs between creativity and conformity in approaches to managing information flow. This is because the study identified cases (5\% of the survey respondents) in which information flow was individual-focused i.e. companies allowed designers and engineers to make use of intuitive and individual approaches for modelling information flow. This attitude for analysing and managing information flow on one hand could foster timely delivery of a PSS. This is because approaches based on individual initiatives may allow individuals to apply approaches best suited to their mode of operation thereby fostering timeliness in the individual's results or output. On the hand, issues of compatibility and continuity in functions of a PSS may require a company to impose standard information flow approaches. With regards to compatibility in the functions of a PSS, the use of common tools such as DFD could serve as a starting point for modelling information flow. This study suggests the popular use (42.5\% of survey respondents) of DFD for modelling products and services. This is in comparison to the DSM approach which was used by $10 \%$ of respondents and IDEFØ, Petri Nets, GRAI or IPO charts which were not used by any of the respondents. This suggestion correlates with assertions in literature that highlight the common use and wide spread support for DFD by most Computer-Aided Software Engineering (CASE) tools [5].

\section{Conclusions}

The paper presents the findings of a survey to capture information flow for productservice systems (PSS) based on a sample of 100 microsystems companies. In literature, textual, audio, video and graphical media forms of nature have been identified for maintaining information flow and for exchanging ideas among system developers and implementers. Furthermore, the use of modelling tools has been promoted in research for defining and representing information flow in organisations and systems.

As indicated by the results of 40 respondents to the survey, information flow in terms of communication, analysis, description and documentation of microsystem functions, is largely motivated by the nature of businesses. In addition, the survey showed that 17 of the respondents have used Data Flow Diagrams and 4 respondents have used Design Structure Matrices. None of the respondents made use of Integrated DEFinition (IDEFØ), Graphes à Résultats et Activités Interreliés (GRAI) grids, Petri nets or Input-Process-Output (IPO) charts. The study also highlights the importance of emphasis on business-driven information flows, simplicity of information flows and trade-offs between creativity/conformity in managing information flow.

Future work will focus on the implications of this study to propose techniques for simplifying and emphasising business-driven information flow for microsystem 
companies within the context of PSS. This study presents an initial attempt to investigate information flow modelling in microsystem companies. Further studies are therefore recommended to evaluate how the findings of the survey compare with other domains and the wider implications of modelling information flow for PSS in terms of promoting creativity and conformity in companies.

Acknowledgements. The authors would like to extend their sincere thanks to the Engineering and Physical Sciences Research Council (EPSRC), for its support via the Cranfield Innovative Manufacturing Research Centre (IMRC), towards the work carried out in the preparation of this paper. Also the authors would like to thank all the participants that took part in the survey.

\section{References}

1. Morelli, N.: Developing new product service systems (PSS): methodologies and operational tools. J. Clean Prod. 14, 1495-1501 (2006)

2. Fujita, H.: Two decades of MEMS - from surprise to enterprise. In: IEEE MEMS Conf., pp. 1-6 (2007)

3. Durugbo, C., Tiwari, A., Alcock, J.R.: An Infodynamic Engine Approach to Improving the Efficiency of Information Flow in a Product-Service System. In: Proceedings of the 1st CIRP IPS2 Conference, pp. 107-112 (2009)

4. Baines, T.S., Lightfoot, H.W., Evans, S., Neely, A., Greenough, R., Peppard, J., Roy, R., Shehab, E., Braganza, A., Tiwari, A., Alcock, J.R., Angus, J.P., Basti, M., Cousens, A., Irving, P., Johnson, M., Kingston, J., Lockett, H., Martinez, V., Michele, P., Tranfield, D., Walton, I.M., Wilson, H.: State-of-the-art in product-service systems. P I Mech. Eng. B-J. Eng. 221, 1543-1552 (2007)

5. Durugbo, C., Tiwari, A., Alcock, J.R.: A Review of Information Flow Diagrammatic Models for Product-Service Systems. Submitted to Int. J. Adv. Manuf. Tech. (2009)

6. Perry, M.J., Fruchter, R., Spinelli, G.: Spaces, traces and networked design. In: P Ann HICSS, pp. 112-121 (2001)

7. Doumeingts, G.: GRAI Approach to Designing and Controlling Advanced Manufacturing Systems in CIM Environment. In: Nof, S.Y., Moodie, C.L. (eds.) Advanced Information Technologies for Industrial Material Flow Systems. NATO ASI Series, pp. 461-529. Springer, Berlin (1989)

8. Martin, J., McClure, C.: Diagramming Techniques for Analysts and Programmers. Prentice Hall, Englewood Cliffs (1985)

9. DeMarco, T.: Structured Analysis and System Specification. Yourdon Press, New Jersey (1979)

10. Katzan, H.: Systems Design and Documentation: An Introduction to the HIPO Method. Van Nostrand Reinhold, New York (1976)

11. Hungerford, B.C., Hevner, A.R., Collins, R.W.: Reviewing software diagrams: a cognitive study. IEEE T Software Eng. 30, 82-96 (2004)

12. Durugbo, C., Tiwari, A., Alcock, J.R.: State-of-the-art in Product-Service Systems based Microsystems Production. Submitted to Int. J. Adv. Manuf. Tech. (2009) 